Int. J. Dev. Biol. 53: 605-613 (2009)

doi: $10.1387 / \mathrm{ijdb} .082607 \mathrm{ah}$

\title{
Large-scale production of growing oocytes in vitro from neonatal mouse ovaries
}

\author{
ARATA HONDA ${ }^{1, \#}$, MICHIKO HIROSE ${ }^{1, \#, ~ K I M I K O ~ I N O U E}{ }^{1,4}$, HITOSHI HIURA ${ }^{2, \# \#, ~ H I R O M I ~ M I K I ~}{ }^{1}$, \\ NARUMI OGONUKI ${ }^{1}$, MICHIHIKO SUGIMOTO ${ }^{1}$, KUNIYA ABE ${ }^{1}$, MITO KANATSU-SHINOHARA ${ }^{3}$, \\ TOMOHIRO KONO ${ }^{2}$, TAKASHI SHINOHARA ${ }^{3}$ and ATSUO OGURA*, ${ }^{* 1,4,5}$

\begin{abstract}
${ }^{1}$ Bioresource Center, RIKEN, Tsukuba, Ibaraki, ${ }^{2}$ Department of BioScience, Tokyo University of Agriculture, Setagaya-ku, Tokyo, ${ }^{3}$ Department of Molecular Genetics, Graduate School of Medicine, Kyoto University, Kyoto, ${ }^{4}$ Graduate School of Life and Environmental Sciences, University of Tsukuba, Tsukuba, Ibaraki and ${ }^{5}$ The Center for Disease Biology and Integrative Medicine, Faculty of Medicine, University of Tokyo, Bunkyo-ku, Tokyo, Japan
\end{abstract}

\begin{abstract}
Although fetal or neonatal mammalian ovaries contain many non-growing oocytes within primordial follicles, most degenerate and only a few contribute to the oocyte pool in the mature ovary. Here, we report a follicle-free culture system that allows a large number of these arrested oocytes to enter the growth phase in vitro. As many as $\mathbf{8 0 0}$ oocytes from a newborn mouse, corresponding to more than $10^{4}$ oocytes in large animals, continued to develop, formed a zona pellucida, and were able to fuse with spermatozoa. Some oocytes reached the size of those in normal antral follicles and entered metaphase $\mathrm{l}$, indicating the completion of the growth phase. The key to success was the sequential provision of essential nutrients and growth factors to the oocytes, while preventing the apoptosis that normally occurs in the majority of growing oocytes in vivo. Importantly, maternal genomic imprinting, which is necessary for normal embryonic development, was imposed correctly on their genomes autonomously. Thus, arrested primordial oocytes can be rescued effectively in vitro and can undergo the morphological and genomic modifications necessary for fertilization and subsequent embryonic development. This culture system may provide a significant impetus to the development of new techniques for the efficient production of oocytes from fetal or neonatal ovaries, for research, clinical, and zoological purposes.
\end{abstract}

KEY WORDS: theca cell, follicle, stem cell factor, genomic imprinting

\section{Introduction}

Mammalian oogenesis starts in the female fetus. When primordial germ cells or oogonia reach the fetal gonads and become oocytes, they become arrested at the diplotene stage of meiotic prophase I. They are packaged into primordial follicles, consisting of a single layer of granulosa cells, during the late fetal stages in many domestic species, or just after birth in mice, and remain in these small follicles until they enter the growth phase (Hirshfield, 1991; van den Hurk and Zhao, 2005). When the primordial oocytes start to grow and proceed through the different stages of development, they undergo a progressive series of morphological and genomic modifications. It is clear that during their development-especially in the growth phase-follicle cell support is essential to provide the oocytes with nutrients and metabolic regulators. This is why the follicular structure is critical for the induction of oocyte growth in vitro. Indeed, oocytes grow poorly or degenerate during culture when they are separated from granu-

Abbreviations used in this paper: ESM, embryonic stem cell medium; GSM, germline stem cell medium; SCF, stem cell factor.

\footnotetext{
*Address correspondence to: Atsuo Ogura. Bioresource Center, RIKEN, 3-1-1, Tsukuba, Ibaraki 305-0074, Japan. Fax: +81-29-836-9172. e-mail: ogura@rtc.riken.go.jp
}

Supplementary Material for this paper (two figures) is available at: http://dx.doi.org/10.1387/ijdb.082607ah

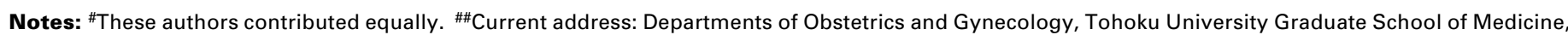
Sendai, Japan.

Accepted: 12 May 2008. Published online: 12 January 2009. 
losa cells (Brower and Schultz, 1982; Haghighat and Van Winkle, 1990). In vitro oocyte growth systems are most advanced in mouse models, with the successful production of normal offspring from the primordial oocytes of newborn mice (Eppig and O'Brien, 1996) or from fetal germ cells using nuclear exchange techniques (Obata and Kono, 2002). Thus, primary oocytes can complete their growth phase to resume meiosis and undergo fertilization if the follicular cells nurse the oocytes correctly.

Despite these advances, the numbers of growing oocytes obtained during in vitro growth experiments are significantly lower than the numbers of primary oocytes found in neonatal ovaries (more than 2,000 at two days after birth; Canning et al., 2003). This is primarily attributable to the programmed cell death (apoptosis) of the oocytes during culture, which also occurs normally during follicular atresia in developing ovaries (De Felici et al., 2005). Mechanical and enzymatic damage to the oocytes at the time of ovary dissection and the inadequacy of culture conditions might also reduce the number of living oocytes. Thus, the efficient production of growing oocytes in vitro depends on the development of better methods of isolating primordial oocytes from ovaries and the optimization of conditions for the growth of oocytes in vitro. However, the complexity of the developmental orchestration of the oocytes and the surrounding follicular cells has been an obstacle to the precise analysis of the events controlling oogenesis. An ideal oocyte culture system would be one in which the oocytes undergo normal growth without any supporting cells in a defined culture milieu, so that the direct effects of factors on oocyte development can be determined precisely.

Recently, we found that crude suspensions of neonatal ovarian cells form round spherical colonies under serum-free conditions when the adherent cells are depleted from the culture. The colonies are composed exclusively of putative thecal stem cells
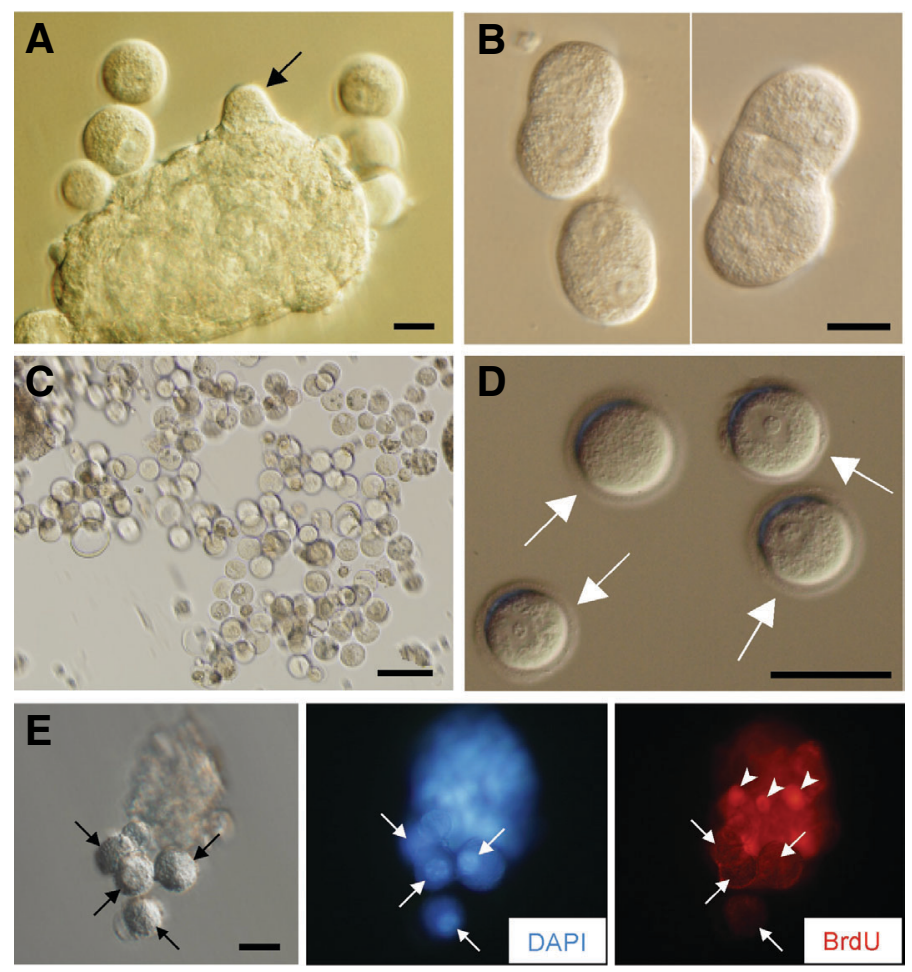

and primordial oocytes (Honda et al., 2007). With the addition of a stem cell factor (SCF, c-Kit ligand) to the medium, naked oocytes are released from the colonies individually or as germ cell cysts. This study was undertaken to test whether these freed oocytes can develop in vitro without supporting cells and whether they can be used for the sorts of biochemical analyses that are usually difficult to perform in the presence of somatic cell contaminants. The somatic-cell-free culture system developed in this study and the information obtained from it may lead to a better understanding of the mechanisms underlying oogenesis and provide some clues to the development of new systems for efficient oocyte production in vitro.

\section{Results}

\section{Preparation and culture of oocytes}

We have previously reported a method of isolating putative thecal stem cells from newborn mouse ovaries through selective culture (Honda et al., 2007). With this method, granulosa cells and other adherent cells (mostly fibroblast cells) were depleted from the culture, which was confirmed by the lack of expression of their marker genes (Honda et al., 2007). The remaining thecal stem cells formed free spherical colonies when they were cultured in serum-free germline stem cell medium (GSM). Many of the primordial oocytes that had existed in the ovaries were incorporated into these colonies. As the thecal stem cells proliferated and the colonies increased in size, the oocytes inside the colonies started to protrude from the surface after 8-10 days in culture. The presence of SCF did not affect the timing of oocyte protrusion, but it apparently increased their numbers on the surfaces of the colonies (data not shown). The oocytes became detached from the colonies individually or as germ cell cysts (Pepling and Spradling, 2001; Fig. 1A, B). The oocytes released into the medium were about 15-20 $\mu \mathrm{m}$ in diameter and had no granulosa cells or zona pellucida (ZP). They were all inferred to be preexisting oocytes because they had previously stained positively for the germ cell marker, mouse vasa homologue (MVH), and produced a negative result in a cell proliferation assay (Honda et al., 2007). The oocytes started to grow without any supporting somatic cells in the same culture medium containing SCF (Fig. 1C). They reached about $35 \mu \mathrm{m}$ in diameter and formed a ZP within 16-20 days (Fig. 1D). They retained normal chromosomal integrity, as indicated by the formation of tetrad chromosomes after the induction of chromosomal condensation within the MII ooplasm (Supplementary Figure 1). The 5-bromo-2'-deoxyuridine (BrdU)incorporation assay demonstrated that the protruding oocytes

Fig. 1. Mouse oocytes emerging from thecal stem cell colonies. Primordial oocytes protruded from the surfaces of thecal stem cell colonies (arrows in A) and were released individually (A) or as germline cysts (B). The germline cysts on the right consist of four oocytes, each of which is slightly larger than those on the left. The released oocytes continued to develop without follicular cell support (C) and formed the ZP (arrows in (D)). Oocytes emerging from colonies were most likely preexisting prophase l oocytes because they showed no signs of proliferation (BrdU-negative; arrows in (E)). The thecal stem cells in the colony were BrdU-positive, indicating their active proliferation and DNA synthesis (arrowheads in E). The oocytes were deformed during the fixation and staining processes. Scale bars: $20 \mu \mathrm{m}$ (A, B, D, and E) and $100 \mu \mathrm{m}$ (D). Hoffman interference contrast optics images. 
were completely negative, whereas the cells in the colonies were stained, reflecting the incorporation of BrdU into their DNA (Fig. 1E). Thus, these SCF-responsive oocytes were derived from preexisting mitotically inactive oocytes, and not from any presumptive female germline stem cells (Johnson et al., 2004).

In another series of experiments, we prepared ovarian cell suspensions from 4-, 9-, and 14-day-old female mice and cultured them in parallel. Thecal cell colonies and naked oocytes were collected from each group, but their numbers apparently decreased with the age of the mice. Even under optimized culture

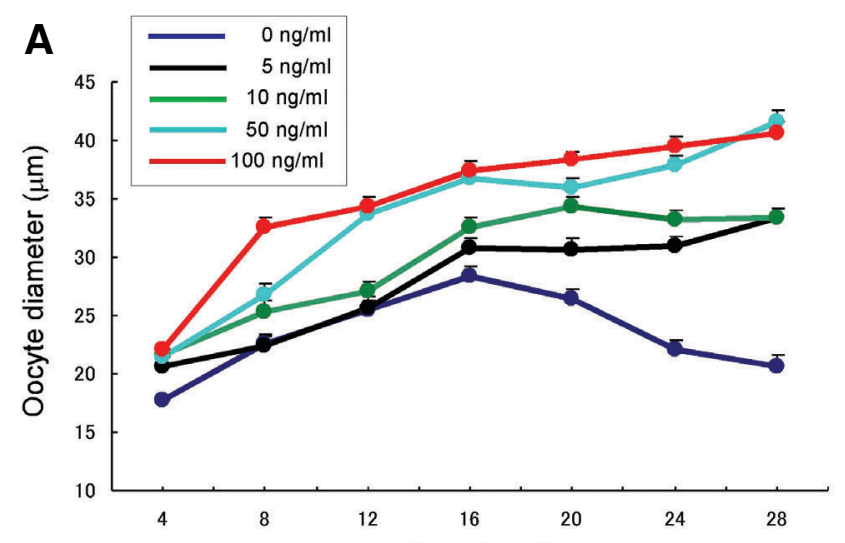

B
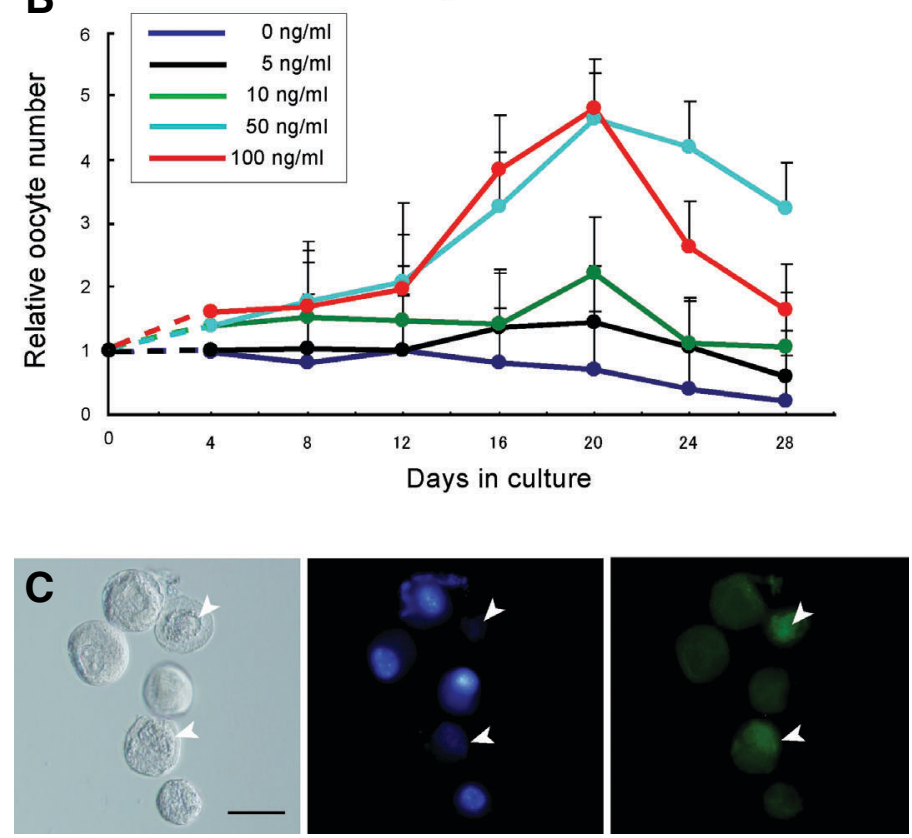

conditions (see below), about 200 and 50 oocytes were collected from each female in the 9- and 14-day-old groups, respectively, whereas more than 800 were recovered from the four-day-old group.

\section{Optimization of oocyte culture conditions}

As mentioned above, SCF treatment accelerated both the derivation of the oocytes from thecal cell colonies and their subsequent growth in vitro. We then examined whether different SCF concentrations altered the oocyte growth kinetics. The final size of the oocytes depended on the concentration of SCF. Throughout the observation period (28 days), the greatest effect of SCF on oocyte diameter was observed at the highest concentrations (50 and $100 \mathrm{ng} / \mathrm{ml}$; Fig. 2A). The numbers of oocytes released from the colonies also increased in parallel with the SCF concentration (Fig. 2B) during the first 20 days, with about four times more oocytes at $50 \mathrm{ng} / \mathrm{ml}$ and $100 \mathrm{ng} / \mathrm{ml} \mathrm{SCF}$ than in the controls (no SCF) or with $5 \mathrm{ng} / \mathrm{ml} \mathrm{SCF}$. However, many of the oocytes cultured at $100 \mathrm{ng} / \mathrm{ml}$ SCF started to degenerate at day 20 and most had been lost by day 28 (Fig. 2B). Thus, as far as we investigated, the best results in terms of the numbers and sizes of the living oocytes were obtained when they were cultured in $50 \mathrm{ng} /$ $\mathrm{ml} \mathrm{SCF}$. Most oocytes that underwent degeneration in culture were terminal deoxynucleotidyl transferase (TdT)-mediated dUTP nick-end-labeling (TUNEL) positive (Fig. 2C), irrespective of their size and the day of culture, indicating that apoptosis occurred in these oocytes as it does during atresia in vivo.

We confirmed that the oocytes growing in vitro without somatic cells expressed Kit as well as other oocyte-specific genes, including Zp1 (zona pellucida 1) and Mvh (mouse vasa homolog; Fig. $3 \mathrm{~A})$, similar to oocytes growing in vivo. Kit receptors were also

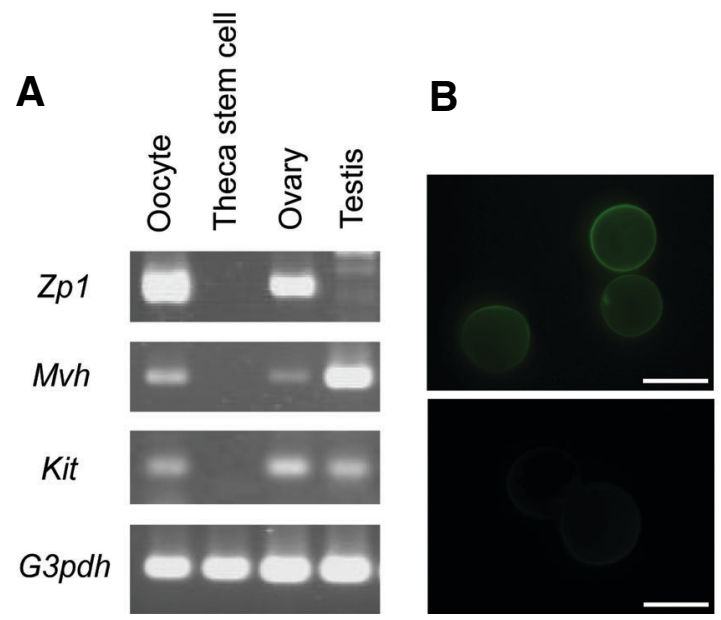

Fig. 2 (Left). Effects of stem cell factor (SCF) on the development of oocytes in vitro. (A) The mean oocyte diameter increased with days in culture, reaching a maximum size at 50 or $100 \mathrm{ng} / \mathrm{ml}$ of SCF. (B) The numbers of oocytes (> $30 \mu \mathrm{m}$ in diameter) released from the colonies increased until day 20 of culture, but thereafter they decreased with oocyte death. Throughout culture, $50 \mathrm{ng} / \mathrm{m} / \mathrm{SCF}$ gave the best results in terms of the sizes and survival rates of the oocytes. (C) Oocytes underwent degeneration by apoptotic cell death, as detected by TUNEL staining. Apoptotic oocytes (arrowheads) were labeled with FITC (green on the right) but not with Hoechst dye (blue in the middle). The oocytes were deformed during the fixation and staining processes. Scale bar: $20 \mu \mathrm{m}$.

Fig. 3 (Right). Gene expression patterns of growing oocytes and the localization of the Kit receptors on the oocyte surface. (A) Oocytes growing in vitro without somatic cells correctly expressed three oocyte marker genes, Zp1, Mvh, and Kit. The testicular tissue also expressed Mvh and Kit. Thecal cells did not express Kit because they were in the stem cell state and very immature. (B) Kit receptor proteins were clearly localized on the surfaces of oocytes growing in vitro by staining with a specific antibody (upper). Oocytes stained with normal goat serum showed no fluorescence (bottom). 
Fig. 4. Effects of basal medium, thecal stem cells, and serum on the development of oocytes. (A) The mean numbers of oocytes obtained from the ovaries of neonates reached more than 800 after 22 days of culture when embryonic stem cell medium (ESM) was used as the basal medium (significantly different from the germline stem cell medium (GSM) group; $\mathrm{P}<0.001)$. (B) ESM also sustained the survival of the oocytes better than did GSM. The survival rates were significantly different between the two groups at 25 and 40 days $(\mathrm{P}<0.001)$. (C) Effects of thecal stem cells and serum on oocyte diameter. Thecal stem cells and serum synergistically accelerated the development of the oocytes. Error bars represent the SD. The lines connecting two bars indicate statistically significant differences between values at $\mathrm{P}<0.01$ (without asterisk) or $\mathrm{P}<$ 0.001 (with asterisk).

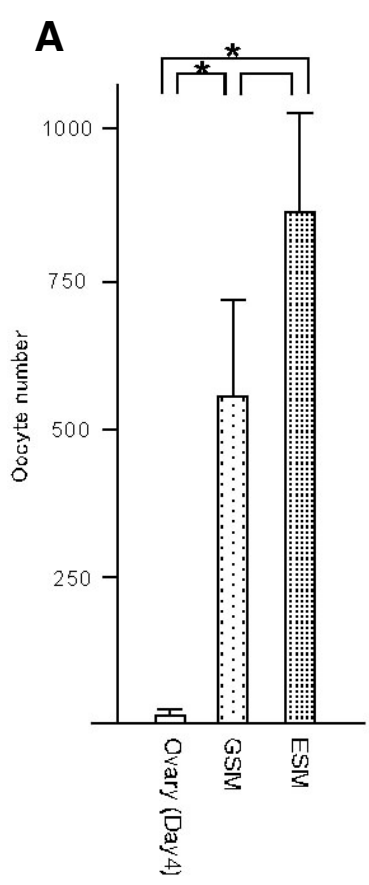

B

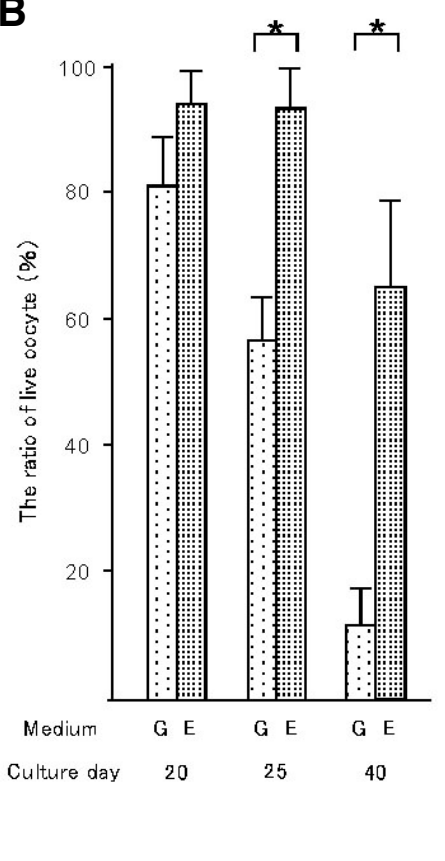

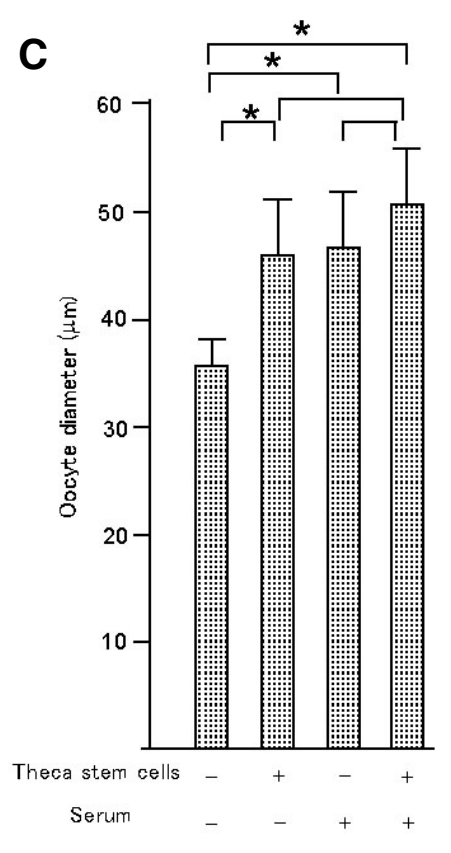

correctly localized on the surfaces of these growing oocytes (Fig. 3B).

We initially used GSM as the basal medium for the in vitro growth of oocytes because this medium had been used successfully for the isolation and culture of thecal stem cells (Honda et al., 2007). However, we found that a simpler medium, embryonic stem cell medium (ESM) with SCF but without serum, gave better results. Significantly, better grown oocytes ( $>30 \mu \mathrm{m}$ diameter) were obtained with ESM than with GSM (861.0 \pm 62.9 vs. 553.6 \pm 59.7 per animal, respectively; $P<0.01$; Fig. 4A). Furthermore, ESM seemed to protect the oocyte against degeneration, which started on day 20. In ESM, more than $90 \%$ of the oocytes were alive at day 25 , whereas fewer than $60 \%$ of the oocytes survived in GSM $(P<0.001$; Fig. 4B). Even at day 40 , more than $60 \%$ of the oocytes were alive in ESM (Fig. 4B).

Thus, oocytes growing under these conditions survived for 40 days in ESM, but they remained the size they had reached on day 16 (around $35 \mu \mathrm{m}$ diameter). We then tested whether other factors promoted oocyte growth. Oocytes that had been cultured in GSM containing $50 \mathrm{ng} /$ $\mathrm{ml} \mathrm{SCF}$ for 10 days were cultured for 10 days more in the presence of serum and/or thecal cells. As shown in Figure $4 \mathrm{C}$, both serum and thecal cells had significant effects on oocyte development $(P<0.001)$, increasing their mean diameter to about $45 \mu \mathrm{m}$. Figure $5 \mathrm{~A}$ shows a group of oocytes developing in the presence of thecal stem cell

Fig. 5. Oocytes in the late growth phase. (A) A group of oocytes developing in vitro in the presence of thecal stem cell colonies (arrows) after 20 days in embryonic stem cell medium (ESM). Most oocytes were still alive without the need for the support of granulosa cells. Scale bar: $500 \mu \mathrm{m}$. (B) Oocytes reaching their maximum normal size (around $70 \mu \mathrm{m}$ ) after 30 days of coculture with thecal cells in serum-containing EMS. Scale bar: $50 \mu \mathrm{m}$. colonies in ESM. The combination of thecal cells and serum further accelerated the development of the oocytes to about 50 $\mu \mathrm{m}$ in diameter (Fig. 4C). During prolonged culture with serum and thecal cells ( 32 days in total), some oocytes reached around 70 $\mu \mathrm{m}$ (Fig. 5B), which is similar to that of fully grown oocytes in antral follicles in vivo.

\section{Fusing capacity of oocytes growing in vitro}

To test the capacity of oocytes growing in vitro to fuse with spermatozoa, an in vitro fertilization assay was performed using capacitated spermatozoa. ZP-free oocytes that had developed for 21 days in either GSM or ESM in the presence of SCF were treated with Hoechst 33342, washed, and then inseminated. More

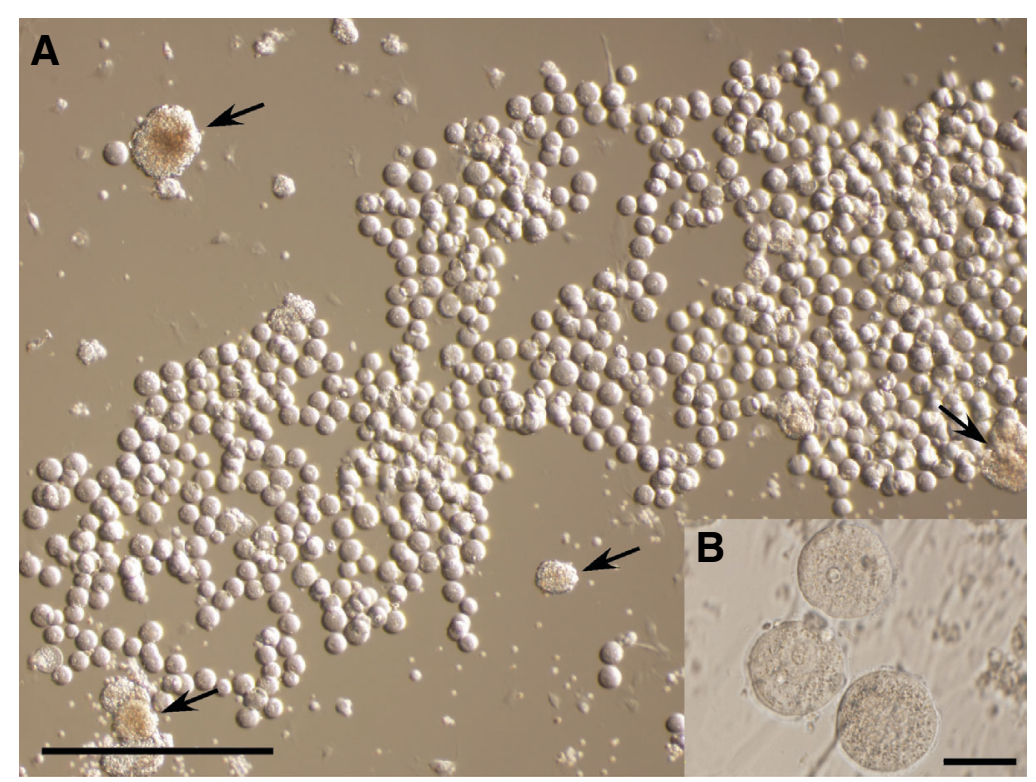



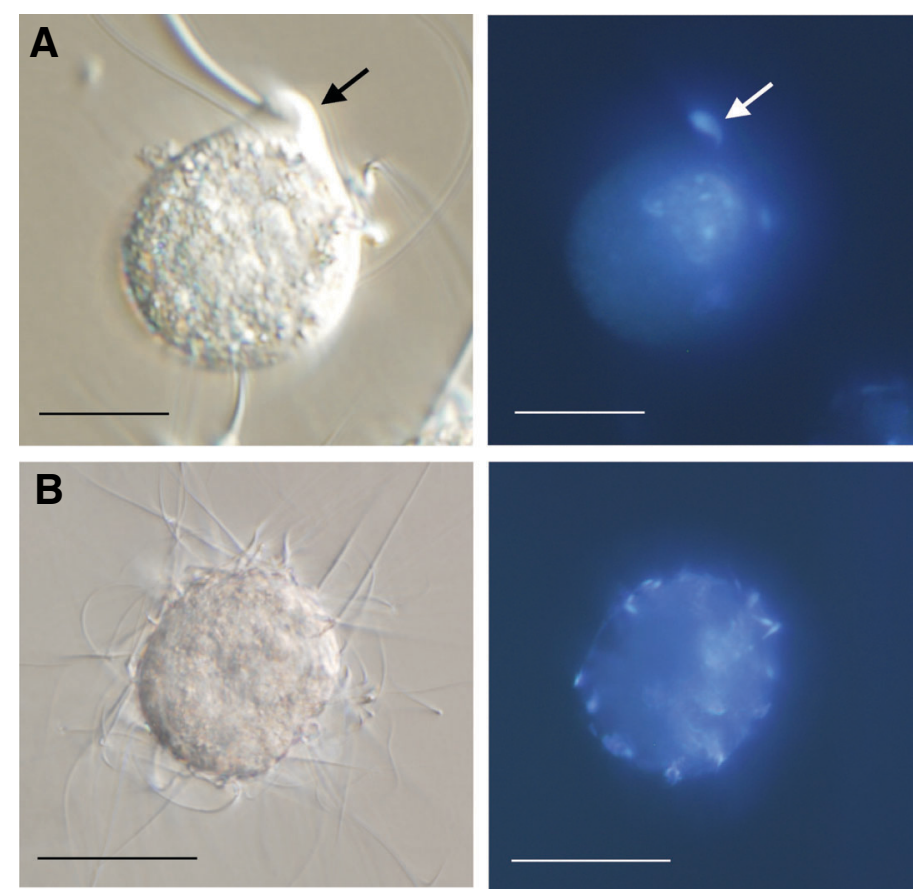

Fig. 6. Assessment of the fusion capacity of oocytes growing in vitro. Both small (A) and large (B) oocytes could fuse with spermatozoa, observed as the transfer of Hoechst dye from the ooplasm to the sperm nucleus. The smaller oocyte shows a fertilization cone (arrow), normally found in fertilized oocytes. Scale bars: $20 \mu \mathrm{m}$ (A) and $50 \mu \mathrm{m}$ (B).

than $70 \%$ of the oocytes examined had fused with the spermatozoa, as demonstrated by the transfer of the fluorescent dye to the sperm nucleus (Fig. 6A, B). Some oocytes showed fertilization cones in which a sperm head could be seen (Fig. 6A).

\section{Meiotic resumption by oocytes growing in vitro}

The nucleolar configurations of the oocytes were visualized with Hoechst 33342 staining after sequential treatment with N6,O2-dibutyryl adenosine-3',5' cyclic-monophosphate (dbcAMP) and okadaic acid, as reported by Chesnel et al. (1994). About 10\% of the oocytes had a bright ring around the nucleolus of their germinal vesicles (Fig. 7A). Such oocytes are the so-called "surrounded nucleolus" (SN) type, and are usually deemed to be oocytes with a higher capacity to undergo meiosis and develop into blastocysts (Zuccotti et al., 2002). After a further 24 hours in culture, some (7/140) oocytes had entered metaphase I, with their condensed chromosomes aligned on the metaphase plate clearly visible with aceto-orcein staining (Fig. 7C). The remaining oocytes had no dye-positive ring around the nucleolus: the so-called "nonsurrounded nucleolus" (NSN) type (Fig. 7B). We found that okadaic acid treatment alone could also induce meiosis, but no SN-type oocytes were observed.

\section{Methylation status of imprinted genes in oocytes growing in vitro}

Three groups of oocytes of different sizes (30-40 $\mu \mathrm{m}, 40-50$ $\mu \mathrm{m}$, and 50-60 $\mu \mathrm{m}$ ) were subjected to DNA methylation analysis of the differentially methylated regions (DMRs) of Igf2r and Zac1 (maternally imprinted genes) and $\mathrm{H} 19$ (paternally imprinted gene). The results clearly showed that oocyte-size-dependent methylation progressed correctly in the two maternally imprinted genes (Igf2r and Zac1), with $73 \%$ and $80 \%$ of $\mathrm{CpG}$ regions methylated, respectively, in oocytes with 50-60 $\mu \mathrm{m}$ diameters (Fig. 8). The paternally imprinted gene, $\mathrm{H} 19$, remained unmethylated. This oocyte-size-dependent methylation imposition pattern was similar to that found in oocytes growing in vivo (Supplementary Fig. 2).

\section{Discussion}

This study demonstrates that the large-scale culture of growing oocytes from mouse neonatal ovaries is possible without the need for follicular cell support. The protocol optimized in this study for the preparation and culture of growing oocytes is shown in Figure 9 , together with the developmental parameters of the oocytes. This finding is intriguing because it has been broadly accepted that follicle cells-especially granulosa cells-are the key modulators of growing oocytes and are indispensable for oocyte growth in vitro (Eppig et al., 2002; Klinger and De Felici, 2002; van den Hurk and Zhao, 2005). Furthermore, as many as 800 growing oocytes per animal could be recruited from the resting pool of primordial oocytes using this culture system. Primordial follicles in neonatal ovaries are usually very difficult to collect intact; their follicular structure is very fragile. We surmise that the keys to success in this study included the less harmful method of oocyte collection and the use of a sequential culture system, which provided essential nutrients and growth factors while preventing the apoptosis that occurs normally in most growing oocytes in vivo.

The oocyte collection method we used was a modification of that developed for the isolation of thecal stem cells (Honda et al., 2007). By selective culture with a serum-free medium, granulosa cells were effectively depleted from the ovarian cell suspension, together with other adhesive cells, such as fibroblast cells, as
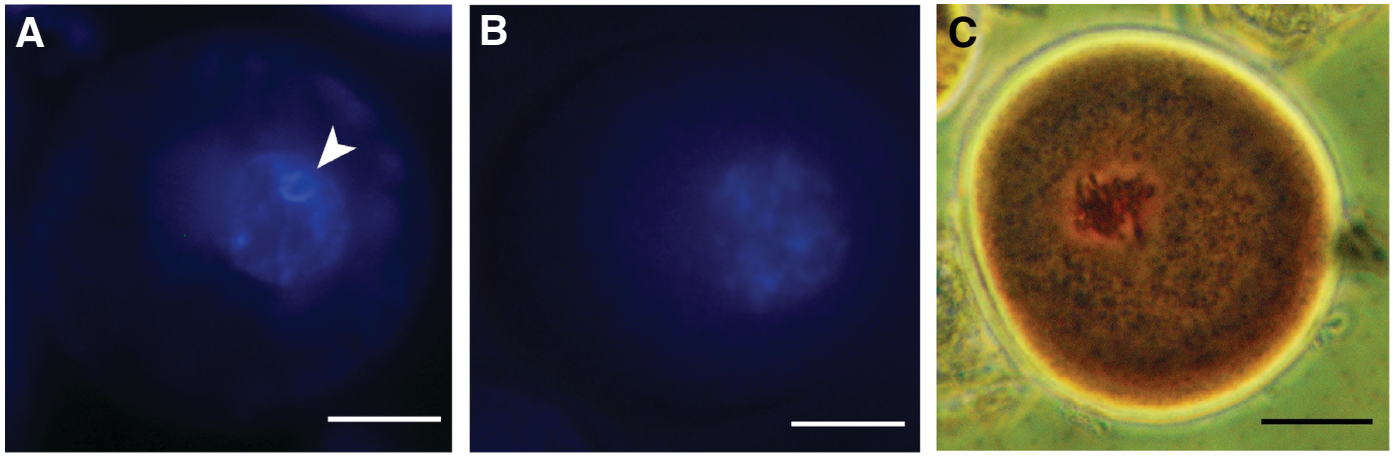

Fig. 7. Oocytes after sequential treatment with dbcAMP and okadaic acid. (A) Some oocytes formed a Hoechst-positive bright ring around the nucleolus of the germinal vesicle (SN type; arrowhead). (B) The remaining oocytes had no bright ring around the nucleolus (NSN type). (C) Oocytes at meiosis I, with completely condensed chromosomes. Scale bars: $20 \mu \mathrm{m}$. 
confirmed by polymerase chain reaction (PCR) using specific primers (Honda et al., 2007). The oocytes freed from the colonies continued to grow, like those recruited into the growing follicle pool in vivo, but without any supporting somatic cells. The culture system used in this study substituted-at least in part-for the somatic-cell-derived factors that normally support the growing oocytes. One of the factors that had a profound effect was SCF (Kit ligand), which also played an important role in the derivation of the oocytes from the thecal cell colonies. SCF is secreted from granulosa cells and acts on the oocyte via the Kit receptor on the oocyte membrane (Hutt et al., 2006). This ligand-receptor interaction activates the PI3K-Akt pathway, which acts as an intraoocyte network for oogenesis in two ways: stimulating growth, while protecting against apoptosis (Liu et al., 2006). This was also true for the action of SCF in vitro, because it produced dose-dependent increases in oocyte size and in the numbers of surviving oocytes. We confirmed that Kit receptors were correctly expressed at both the mRNA and protein levels (Fig. 3). We postulate that the lack of granulosa cells might have also contributed to the survival of the growing oocytes. Fas, a cell-surface receptor molecule that mediates apoptosis, is expressed on granulosa cells and induces follicular atresia, permitting fewer than $1 \%$ of follicles to develop (Sakamaki et al., 1997). Recently, p2 $7^{\mathrm{kip} 1}$ has been identified as another apoptotic inducer expressed in granulosa cells in developing follicles (Rajareddy et al., 2007). Thus, the lack of granulosa cells might have allowed the growing oocytes to escape follicular atresia.

As mentioned above, the oocytes stopped developing on day
$30-40 \mu \mathrm{m}$

$\operatorname{lgf} 2 r$

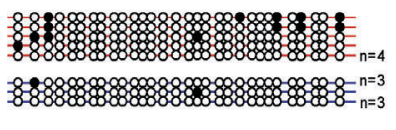

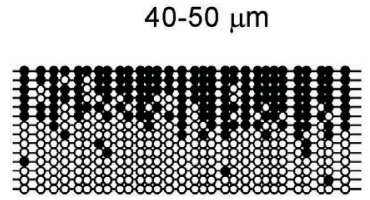

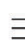

Zac1

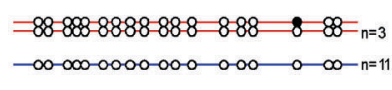

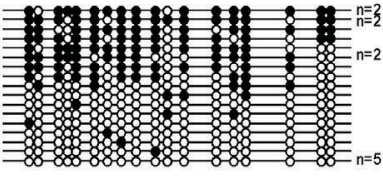

$H 19$
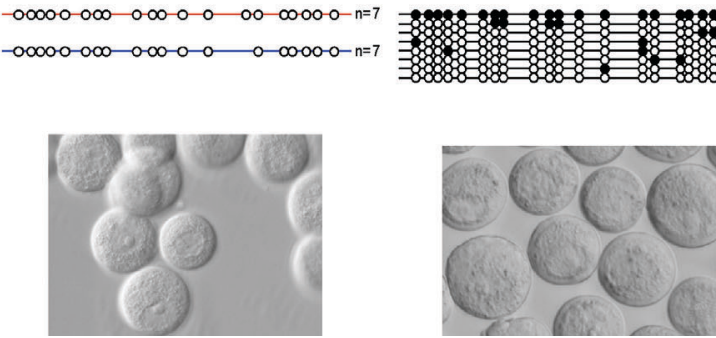

20 in culture and initiated apoptosis. This pattern of oocyte development and degeneration in vitro (illustrated in Fig. 2A, B) may indicate that the requirements for oocyte growth are switched at some time around day 20. Within normal follicles, many nutrients and regulatory factors are supplied to oocytes by the surrounding granulosa cells in a paracrine fashion or directly through the gap junction network shared by the oocytes and granulosa cells. According to a gene knockout study that inhibited gap junction formation by the deletion of Gja4 (the gene encoding connexin 37), gap junctions are necessary for the progression to the preantral follicle stage, but not for early folliculogenesis and initial oocyte growth (Carabatsos et al., 2000). Perhaps the oocyte growth arrest we observed around day 20 reflects the increasing dependency of growing oocytes on gap junctions. Interestingly, we found that this oocyte degeneration by apoptosis was ameliorated considerably by the use of ESM as the basic medium. ESM is a medium formulated for the establishment and maintenance of mouse embryonic stem cells and contains leukemia inhibitory factor (LIF) as its sole growth factor. By contrast, the GSM we initially used was developed for male germline stem cells (Kanatsu-Shinohara et al., 2003) and contains many growth factors. Small metabolites, such as energy substrates, nucleotides, and amino acids, are transferred through gap junctions to growing oocytes (Eppig et al., 2005). The composition of the ESM medium was possibly better suited to supply these small molecules to the naked oocytes in our culture system.

Besides oocyte survival, another important goal during oocyte growth in vitro is to attain a meiotically competent size (around 70
$50-60 \mu \mathrm{m}$
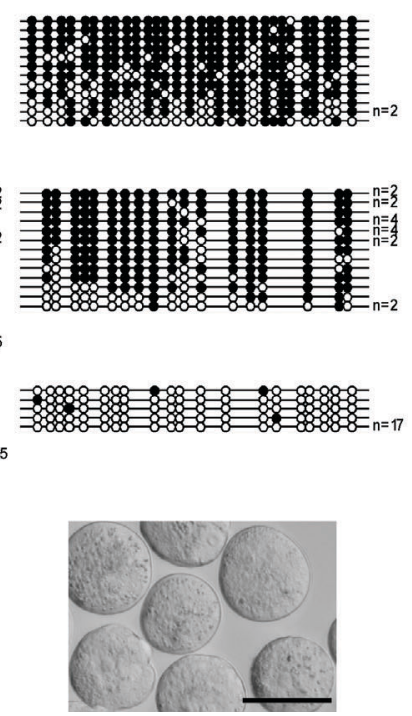

Fig. 8. The methylation status of the differentially methylated regions of three imprinted genes, Igf2r, Zac1, and H19, in three oocyte groups of different sizes. Each horizontal line indicates the sequence from a single clone if the number of clones is not indicated. Open circles represent unmethylated $C p G$ sequences and filled circles indicate methylated CpGs. Because the oocytes with 30-40 $\mu$ m diameters were derived from (B6 X JF1) strain mice and had allelic polymorphisms, the maternal and paternal alleles are indicated by red and blue lines, respectively. The methylation patterns of the two maternally imprinted genes, Igf2r and Zac1, suggest that genomic imprinting was established in an oocyte-size-dependent manner. These methylation patterns are very similar to those of oocytes grown in vivo (see Supplementary Fig. 2). The paternally imprinted gene $\mathrm{H} 19$ remained unmethylated, irrespective of the size of the oocyte. Representative photographs of each oocyte group are shown at the bottom. Scale bars: $50 \mu \mathrm{m}$. as the basic medium significantly improved the survival of the oocytes, but did not further increase their size. This obstacle was overcome by the addition of serum to the medium or by coculture with thecal stem cells. We have not determined the optimal concentration of serum or the optimal density of thecal cells for this culture system. However, these two treatments seemed to act synergistically on oogenesis because the best result, in terms of the size of oocytes $(50 \mu \mathrm{m}$ mean diameter at day 25), was obtained when they were cultured in the presence of both factors. It will be interesting to identify the paracrine factors that are secreted from thecal cells to stimulate oocyte growth, because thecal cells are generally thought to supply steroid hormone sources or keratinocyte growth factors (Kezele et al., 2005).

Normally, as oocytes grow in follicles, they undergo a series of nuclear and cytoplasmic modifications necessary for final oocyte $\mu \mathrm{m}$ in diameter). The use of ESM 


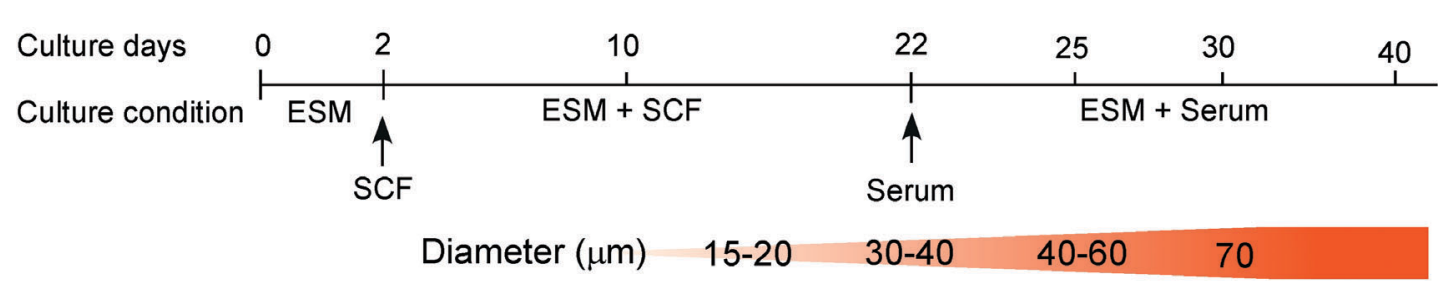

Degeneration (\%) 10 $40-50$

$$
\begin{aligned}
& \text { Maternal } \\
& \text { imprinting }
\end{aligned}
$$

was correctly imposed on the genomes of the growing oocytes. Without these maternal gene imprints, mammalian embryos cannot survive to term, as clearly demonstrated by the nuclear exchange experiments of Kono et al. (2002, 2004). The maternal imprint is imposed sequentially on the oocyte genome in an oocyte-size-dependent manner (Hiura et al., 2006). Our DNA methylation analysis of two imprinted genes in growing oocytes of different diameters showed a cor-

Fig. 9. Schematic diagram of the follicle-free in vitro oocyte growth system optimized in this study. The protocol includes the use of embryonic stem cell medium (ESM) as the basal medium and treatment with stem cell factor (SCF) during the first half of culture, followed by treatment with serum in the second half of culture. As mentioned in the text, coculture with thecal stem cells was also beneficial for oocyte growth. The corresponding features of the developing oocytes are indicated.

maturation and fertilization and for subsequent embryonic development. Our next undertaking was to determine whether oocytes growing in vitro showed signs of such developmental competence based on an autonomous program without supporting somatic cells. First, we examined the capacity of the oocytes to fuse with spermatozoa, using an in vitro fertilization assay. Within the ovary, growing oocytes become capable of fusion with spermatozoa as soon as they reach about $20 \mu \mathrm{m}$ in diameter (Zuccotti et al., 1994). Therefore, because it was very probable that growing oocytes could fuse with spermatozoa shortly after the initiation of culture, we examined whether the oocytes growing alone in culture retained their fusion capacity. Our result clearly indicated that the majority of oocytes retained this capacity even after 21 days in culture. Second, we tested whether oocytes growing in vitro resumed meiosis and entered metaphase. Some of the oocytes that had grown for 26 days in culture underwent germinal vesicle breakdown (GVBD) and complete chromosomal condensation after treatment with okadaic acid, an inhibitor of phosphatases $1 \mathrm{~A}$ and $2 \mathrm{~A}$. This finding suggests that the oocytes might have accumulated the factors (e.g., p34cd2, cyclin B1, and cdc25; Kanatsu-Shinohara et al., 2000) required for proceeding to metaphase I. Following treatment with dbcAMP, the nuclei of some oocytes showed a ring of Hoechst 33342-positive chromatin around the nucleolus (Fig. 7A). This SN nucleolar configuration appears in a subpopulation of oocytes in vivo and correlates well with meiotic competence and embryonic development (Zuccotti et al., 2002; Inoue et al., 2007). Because a high level of cAMP is supplemented by the surrounding granulosa cells through gap junctions (van den Hurk and Zhao, 2005), this dbcAMP treatment might have improved the quality of the granulosa-free oocytes. Thus, we succeeded in reproducing this process in oocytes growing in vitro to the metaphase I stage, although they did not complete meiosis to metaphase II. In this study, however, the proportion of oocytes reaching metaphase I (5\%) was still lower than that of oocytes cultured with granulosa cells (35/150, $23 \%$; Klinger and de Felici, 2002). It is probable that the acquisition of meiotic competence by growing oocytes is highly dependent on the accompanying granulosa cells and that improvements in somatic-cell-free culture conditions are still required for the efficient derivation of meiosis-competent oocytes in vitro.

Finally, we examined whether maternal genomic imprinting rect size-dependent methylation pattern. This result has important implications for biology in that mammalian maternal genomic imprinting was established in these oocytes autonomously, independent of the follicular environment.

The application of technology to the growth and maturation of oocytes from the most abundant primordial follicles holds many attractions for clinical practice, animal production technology, and research. The somatic-cell-free culture system we have developed allows precise biochemical analyses, which are usually difficult to perform in the presence of somatic cell contaminants. Indeed, we could readily obtain data on the imprinting status of the growing oocytes, which usually requires laborious work to remove the surrounding granulosa cells. We also expect that some unknown oogenesis-related proteins (e.g., sperm-egg fusion proteins) might now be identified, because they can be purified efficiently from a bulk culture of growing oocytes. Furthermore, the information obtained under different culture conditions may lead to a better understanding of the mechanisms underlying oogenesis and offer some clues to the development of new systems of efficient oocyte production in vitro.

\section{Materials and Methods}

\section{Cell preparation and culture}

About 20 ovaries of newborn pups (2-4 days after birth) were obtained from ICR, C57BL/6 (B6), or hybrid B6 (Mus musculus musculus) X JF1 (Mus musculus molossinus) F1 mice. Cell culture was initiated according to a protocol for the establishment of putative thecal stem cells, which was modified from a protocol for the establishment of male germline stem cells (Kanatsu-Shinohara et al., 2003; Honda et al., 2007). In brief, isolated ovaries were treated with $1 \mathrm{mg} / \mathrm{ml}$ collagenase in Hanks's solution at 37 ${ }^{\circ} \mathrm{C}$ for 15 minutes and then treated with $0.2 \%$ trypsin and $1.4 \mathrm{mg} / \mathrm{ml}$ DNase for 10 minutes. Loosened ovarian tissues were dissected into single cells by gentle pipetting and were allocated to $6-8$ wells of a $0.1 \%(w / v)$ gelatincoated 24-well tissue culture plate (2.0-2.5 X 105 cells/well). The culture medium was essentially serum-free GSM (Kanatsu-Shinohara et al., 2003). For the primary cell preparation, fibroblast cells were allowed to attach to the bottom of a gelatin-coated culture plate, and only the floating cells were passaged to the secondary culture plate. These replated cells attached weakly to the bottom of the culture wells during overnight culture and formed round colonies consisting of putative thecal stem cells and primordial oocytes. In some experiments, ESM was used. This consists of Dulbecco's modified Eagle's medium (high-glucose DMEM; In vitrogen, 
Carlsbad, CA, USA) containing 15\% knockout serum replacement (KSR; In vitrogen), $10^{3} \mathrm{U} / \mathrm{ml}$ murine LIF (ESGRO; In vitrogen), $2 \mathrm{mM} \mathrm{L-glutamine,}$ $100 \mathrm{nM}$ 2-mercaptoethanol, and nonessential amino acids. The cells were maintained at $37^{\circ} \mathrm{C}$ under $5 \% \mathrm{CO}_{2}$ in air. When serum-containing ESM was prepared, $15 \%$ KSR was replaced with $10 \%$ fetal bovine serum. Half the culture medium was replaced every 2-3 days in all cultures.

In another series of experiments, we prepared ovarian cell suspensions from female mice 4,9 , and 14 days after birth and compared the efficiencies of thecal cell colony formation and the production of growing oocytes in vitro.

\section{In vitro preparation of oocytes}

Two days after the initiation of ovarian cell culture, SCF (Chemicon, Temecula, CA, USA) was added to the cultures at various concentrations $(0,5,10,50$, and $100 \mathrm{ng} / \mathrm{ml})$ and for different periods (0-28 days). The numbers of growing oocytes per unit area or the total in each well were scored.

\section{BrdU-incorporation assay}

To detect DNA synthesis in the growing oocytes in vitro, $100 \mu \mathrm{M} \mathrm{BrdU}$ was dissolved in the medium at the initiation of culture and incubated for two days. The cells were gently washed and cultured for 10 days in the presence of $100 \mathrm{ng} / \mathrm{ml} \mathrm{SCF}$. The incorporation of BrdU was detected using the BrdU Labeling and Detection Kit I (Roche, Basel, Switzerland), according to the manufacturer's protocol.

\section{Detection of apoptosis}

Apoptosis was analyzed by TUNEL, using an in situ apoptosis detection kit (TaKaRa, Shiga, Japan) according to the manufacturer's protocol. Thirty days after the initiation of culture using ESM in the presence of thecal stem cells, the oocytes were collected, washed with phosphatebuffered saline (PBS), and then fixed in $4 \%$ paraformaldehyde/PBS at room temperature for 30 minutes. After the oocytes had been washed three times with PBS, they were treated with permeabilization buffer for 3 minutes on ice. After the oocytes had been washed three more times in PBS, they were incubated in TUNEL reaction mixture containing TdT and dUTP-fluorescein isothiocyanate (FITC) at $37^{\circ} \mathrm{C}$ for 1 hour. After three washes with PBS, the oocytes were incubated in Hoechst 33342. TUNELpositive oocytes were detected by their FITC signal under fluorescence microscopy.

\section{Expression analysis of Kit receptors at the mRNA and protein levels}

Kit gene expression and the localization of the Kit protein product on the oocyte surface were analyzed in oocytes growing in vitro. Using ISOGEN (Nippon Gene, Toyama, Japan), total RNA was extracted from growing oocytes after 18 days in culture, from isolated thecal stem cells, and from the ovaries and testes of 2-3-month-old ICR mice. First-strand cDNA was synthesized using a TaKaRa RNA PCR kit with an oligo(dT)$3^{\prime}$ site adaptor primer. Synthesized cDNA was subjected to PCR using specific primers (Table 1). To localize the Kit receptors on the oocyte surface, growing oocytes that had been cultured in serum-containing ESM in vitro were treated with acidic Tyrode's solution and pipetted several times under a dissecting microscope until the ZP had dissolved (approximately 1 minutes). After the removal of the ZP, the denuded oocytes were washed five times with fresh ESM, and then incubated for

\section{TABLE 1}

\section{PRIMER SETS FOR GENE EXPRESSION ANALYSIS}

\begin{tabular}{lllc} 
Gene & Forward primer & Reverse primer & Product size, bp \\
\hline$Z p 1$ & $5^{\prime}$-ccaatggccgtgtggat-3' & $5^{\text {'-ggtggttggggtgagaaga-3' }}$ & 825 \\
Mvh & $5^{\prime}$-ggtccaaaagtgacatatataccc-3' & $5^{\prime}$-ttggttgatcagttctcgagt-3' & 399 \\
Kit & $5^{\prime}$-gatctgctctgcgtctgtt-3' & $5^{\prime}$-ctgattgtgctggatggatg-3' & 108 \\
G3pdh & $5^{\prime}$-gtgttcctacccccaatgtg-3' & $5^{\prime}$-gtcattgagagcaatgccag-3' & 214 \\
\hline
\end{tabular}

4 hours to allow the surface proteins to recover. The ZP-free oocytes were fixed in $4 \%$ paraformaldehyde/PBS at room temperature for 30 minutes. After the oocytes had been washed five times with PBS, they were incubated in 5\% normal goat serum/PBS at room temperature for 1 hour to block any nonspecific antibody binding sites. The oocytes were then incubated overnight at $4{ }^{\circ} \mathrm{C}$ with polyclonal goat antibody raised against mouse Kit protein (sc-1494; Santa Cruz Biotechnology, Santa Cruz, CA, USA), and then washed five times in $1 \%$ bovine serum albumin/PBS. The oocytes were then exposed to secondary antibody (FITC-conjugated rabbit antigoat IgG; Sigma-Aldrich, St Louis, MO, USA) for 1 hour at room temperature. Oocytes exposed to normal goat serum and then to the secondary antibody were used as the control. The distribution of Kit protein was observed with a fluorescence microscope.

\section{Evaluation of the oocyte chromatin configuration as an index of meiosis resumption competence}

Oocytes growing in vitro never entered metaphase I spontaneously, even after prolonged culture. Therefore, we treated these oocytes sequentially with dbcAMP and okadaic acid, which are known to induce GVBD in oocytes lacking spontaneous meiotic competence (Chesnel et al., 1994; Klinger and De Felici, 2002). The oocytes that had been cultured in SCF-containing ESM for 21 days were treated with $200 \mu \mathrm{M}$ dbcAMP in serum-containing ESM for three days. After the oocytes had been thoroughly washed and cultured in serum-containing ESM for 24 hours, they were treated with $1 \mu \mathrm{M}$ okadaic acid in serum-containing ESM for 3 hours. They were then washed and further cultured in serum-containing ESM for 24 hours. At the end of the culture period, any meiotic resumption by the oocytes was evaluated by staining them with Hoechst 33342 to observe their nucleolar configuration. Some oocytes were selected randomly for whole-mount preparations. They were mounted and compressed between a slide glass and a coverslip, and then fixed with $2.5 \%$ glutaraldehyde in $0.1 \mathrm{M}$ cacodylate buffer $(\mathrm{pH} 7.4)$ for 20 minutes. After the samples had been washed with distilled water and dehydrated with ethanol, they were stained with $1 \%$ aceto-orcein for 1-2 minutes and observed with a phase contrast microscope.

\section{Sperm-oocyte fusion assay}

Cauda epididymal sperm from ICR strain mice were dispersed in 400 $\mu \mathrm{l}$ drops of human tubal fluid (HTF) medium (Quinn et al., 1985) and incubated at $37{ }^{\circ} \mathrm{C}$ under $5 \% \mathrm{CO}_{2}$ in air for 2 hours to induce the capacitation and spontaneous acrosome reactions. Growing oocytes were generated with GSM 20 days after the ovarian cell cultures had been treated with SCF and were transferred to $100 \mu \mathrm{l}$ drops of HTF medium. After three washes with fresh HTF, the oocytes were transferred to HTF drops containing $5 \mu \mathrm{g} / \mathrm{ml}$ Hoechst 33342. They were incubated for a further 15 minutes and then washed four times with fresh HTF medium. To remove the ZP, the oocytes were incubated with acidic Tyrode's solution, as described above. The ZP-free oocytes were washed three times with fresh HTF medium and capacitated spermatozoa (150 sperm/ $\mu$ ) were added and incubated at $37^{\circ} \mathrm{C}$ under $5 \% \mathrm{CO}_{2}$ in air for 30 minutes. The oocytes were then subjected to gentle pipetting to remove the loosely bound sperm, and were transferred to a drop of HTF/0.25\% glutaraldehyde for fixation. To confirm sperm-oocyte fusion, fluorescence microscopy under UV excitation was used to detect the transfer of Hoechst 33342 from the oocyte to the sperm.

\section{Analysis of genomic imprinting status}

Genomic imprinting is erased during the development of primordial germ cells, and the maternal imprint is reestablished during postnatal oocyte growth (Reik and Walter, 2001). The maternal imprint is imposed sequentially on the oocyte genome as the DNA methylation of the DMRs of each imprinted gene in an oocyte-size-dependent manner (Hiura et al., 2006). We examined whether the maternal imprint was established correctly in the genomes of oocytes growing in vitro without follicular support. Three groups of oocytes of different sizes $(30-40 \mu \mathrm{m}, 40-50 \mu \mathrm{m}$, 
and $50-60 \mu \mathrm{m}$ in diameter) were prepared for the analysis. The smallest group $(30-40 \mu \mathrm{m})$ was collected from (B6 X JF1) F1 strain oocytes that had been cultured for 18 days in SCF-containing GSM. The remaining two size groups were collected from ICR strain oocytes that had been cultured for 10 days in GSM followed by 26 days in ESM containing serum. DNA was isolated and subjected to bisulfate-sequencing methylation analysis of the DMRs of the Igf2r, Zac1, and $\mathrm{H} 19$ genes, as described by Hiura et al. (2006). Oocytes growing in vivo were collected from juvenile B6D2F1 mice and used as the controls.

\section{Statistical analysis}

Mean values were compared using one-way ANOVA, following arcsine transformation if necessary. Where appropriate, the significance of differences among the means was determined with Scheffe's $F$ test. $P<$ 0.05 was considered significant. All experiments were replicated at least twice.

\section{Acknowledgments \\ We thank Dr Yuji Hirao for his very helpful discussions and sugges- tions on oocyte survival and apoptosis. This research was supported by grants from MEXT (AH and AO), MHLW (AO), and CREST (AO). AH is the recipient of a research fellowship from the RIKEN Special Postdoctoral Researchers Program. The JF1 mice used in this study belong to Dr T. Shiroishi, National Institute of Genetics (Japan), and were provided by the RIKENBioResource Center with the support of the National BioResources Project of MEXT, Japan.}

\section{References}

BROWER, P. T. and SCHULTZ, R. M. (1982). Intercellular communication between granulosa cells and mouse oocytes: existence and possible nutritional role during oocyte growth. Dev. Biol. 90: 144-153.

CANNING, J., TAKAI, Y. and TILLY, J. L. (2003). Evidence for genetic modifiers of ovarian follicular endowment and development from studies of five inbred mouse strains. Endocrinology 144: 9-12.

CARABATSOS, M. J., SELLITTO, C., GOODENOUGH, D. A. and ALBERTINI, D. F. (2000). Oocyte-granulosa cell heterologous gap junctions are required for the coordination of nuclear and cytoplasmic meiotic competence. Dev. Biol. 226: 167-179.

CHESNEL, F., WIGGLESWORTH, K. and EPPIG, J. J. (1994). Acquisition of meiotic competence by denuded mouse oocytes: participation of somatic-cell product(s) and cAMP. Dev. Biol. 161: 285-295.

DE FELICI, M., KLINGER, F. G., FARINI, D., SCALDAFERRI, M. L., IONA, S. and LOBASCIO, M. (2005). Establishment of oocyte population in the fetal ovary: primordial germ cell proliferation and oocyte programmed cell death. Reprod. Biomed. Online 10: 182-191.

EPPIG, J. J. and O'BRIEN, M. J. (1996). Development in vitro of mouse oocytes from primordial follicles. Biol. Reprod. 54: 197-207.

EPPIG, J. J., WIGGLESWORTH, K. and PENDOLA, F. L. (2002). The mammalian oocyte orchestrates the rate of ovarian follicular development. Proc. Natl Acad. Sci. USA 99: 2890-2894.

EPPIG, J. J., PENDOLA, F. L., WIGGLESWORTH, K. and PENDOLA, J. K. (2005). Mouse oocytes regulate metabolic cooperativity between granulosa cells and oocytes: amino acid transport. Biol. Reprod. 73: 351-357.

HAGHIGHAT, N. and VAN WINKLE, L. J. (1990). Developmental change in follicular cell-enhanced amino acid uptake into mouse oocytes that depends on intact gap junctions and transport system. J. Exp. Zool. 253: 71-82.

HIRSHFIELD, A. N. (1991). Development of follicles in the mammalian ovary. Int. Rev. Cytol. 124, 43-101.

HIURA, H., OBATA, Y., KOMIYAMA, J., SHIRAI, M. and KONO, T. (2006). Oocyte growth-dependent progression of maternal imprinting in mice. Genes Cells 11: 353-361.

HONDA, A., HIROSE, M., HARA, K., MATOBA, S., INOUE, K., MIKI, H., HIURA, H., KANATSU-SHINOHARA, M., KANAI, Y., KONO, T., SHINOHARA, T. and
OGURA, A. (2007). Isolation, characterization and in vitro and in vivo differentiation of putative thecal stem cells. Proc. Natl Acad. Sci. USA 104: 1238912394.

HUTT, K. J., MCLAUGHLIN, E. A. and HOLLAND, M. K. (2006). Kit ligand and cKit have diverse roles during mammalian oogenesis and folliculogenesis. Mol. Hum. Reprod. 12: 61-69.

INOUE, A., AKIYAMA, T., NAGATA, M. and AOKI, F. (2007). The perivitelline space-forming capacity of mouse oocytes is associated with meiotic competence. J. Reprod. Dev. 53: 1043-1052.

JOHNSON, J., CANNING, J., KANEKO, T., PRU, J. K. and TILLY, J. L. (2004). Germline stem cells and follicular renewal in the postnatal mammalian ovary. Nature 428: 145-150.

KANATSU-SHINOHARA, M., SCHULTZ, R. M. and KOPF, G. S. (2000). Acquisition of meiotic competence in mouse oocytes: absolute amounts of p34(cdc2), cyclin B1, cdc25C and wee1 in meiotically incompetent and competent oocytes. Biol. Reprod. 63: 1610-1616.

KANATSU-SHINOHARA, M., OGONUKI, N., INOUE, K., MIKI, H., OGURA, A., TOYOKUNI, S. and SHINOHARA, T. (2003). Long-term proliferation in culture and germline transmission of mouse male germline stem cells. Biol. Reprod. 69: 612-616.

KEZELE, P., NILSSON, E. E. and SKINNER, M. K. (2005). Keratinocyte growth factor acts as a mesenchymal factor that promotes ovarian primordial to primary follicle transition. Biol. Reprod. 73: 967-973.

KLINGER, F. G. and DE FELICI, M. (2002). In vitro development of growing oocytes from fetal mouse oocytes: stage-specific regulation by stem cell factor and granulosa cells. Dev. Biol. 244: 85-95.

KONO, T., SOTOMARU, Y., KATSUZAWA, Y. and DANDOLO, L. (2002). Mouse parthenogenetic embryos with monoallelic $H 19$ expression can develop to day 17.5 of gestation. Dev. Biol. 243: 294-300.

KONO, T., OBATA, Y., WU, Q., NIWA, K., ONO, Y., YAMAMOTO, Y., PARK, E. S., SEO, J. S. and OGAWA, H. (2004). Birth of parthenogenetic mice that can develop to adulthood. Nature 428: 860-864.

LIU, K., RAJAREDDY, S., LIU, L., JAGARLAMUDI, K., BOMAN, K., SELSTAM, G. and REDDY, P. (2006). Control of mammalian oocyte growth and early follicular development by the oocyte PI3 kinase pathway: new roles for an old timer. Dev. Biol. 299: 1-11.

OBATA, Y. and KONO, T. (2002). Maternal primary imprinting is established at a specific time for each gene throughout oocyte growth. J. Biol. Chem. 277: 52855289.

PEPLING, M. E. and SPRADLING, A. C. (2001). Mouse ovarian germ cell cysts undergo programmed breakdown to form primordial follicles. Dev. Biol. 234: 339-351.

QUINN, P., KERIN, J. F. and WARNES, G. M. (1985). Improved pregnancy rate in human in vitro fertilization with the use of a medium based on the composition of human tubal fluid. Fertil. Steril. 44: 493-498.

RAJAREDDY, S., REDDY, P., DU, C., LIU, L., JAGARLAMUDI, K., TANG, W., SHEN, Y., BERTHET, C., PENG, S. L., KALDIS, P. and LIU, K. (2007). p27kip1 (Cdkn1b) controls ovarian development by suppressing follicle endowment and activation and promoting follicle atresia in mice. Mol. Endocrinol. 21: 21892202.

REIK, W. and WALTER, J. (2001). Genomic imprinting: parental influence on the genome. Nat. Rev. Genet. 2: 21-32.

SAKAMAKI, K., YOSHIDA, H., NISHIMURA, Y., NISHIKAWA, S. and MANABE, N., YONEHARA, S. (1997). Involvement of Fas antigen in ovarian follicular atresia and luteolysis. Mol. Reprod. Dev. 47: 11-18.

VAN DEN HURK, R. and ZHAO, J. (2005). Formation of mammalian oocytes and their growth, differentiation and maturation within ovarian follicles. Theriogenology 63: 1717-1751.

ZUCCOTTI, M., PICCINELLI, A., MARZILIANO, N., MASCHERETTI, S. and REDI, C. A. (1994). Development and loss of the ability of mouse oolemma to fuse with spermatozoa. Zygote 2: 333-339.

ZUCCOTTI, M., PONCE, R. H., BOIANI, M., GUIZZARDI, S., GOVONI, P., SCANDROGLIO, R., GARAGNA, S. and REDI, C. A. (2002). The analysis of chromatin organization allows selection of mouse antral oocytes competent for development to blastocyst. Zygote 10: 73-78. 


\section{Further Related Reading, published previously in the Int. J. Dev. Biol.}

See our recent Special Issue Fertilization, in honor of David L. Garbers and edited by Paul M. Wassarman and Victor D. Vacquier at: http://www.ijdb.ehu.es/web/contents.php?vol=52\&issue=5-6

\section{Isolation of apoptotic mouse fetal oocytes by AnnexinV assay} Anna-Maria Lobascio, Francesca-Gioia Klinger and Massimo De Felici Int. J. Dev. Biol. (2007) 51: 157-160

KL/KIT co-expression in mouse fetal oocytes.

Luisa Doneda, Francesca-Gioia Klinger, Lidia Larizza and Massimo De Felici Int. J. Dev. Biol. (2002) 46: 1015-1021

2006 ISI **Impact Factor $=3.577^{* *}$

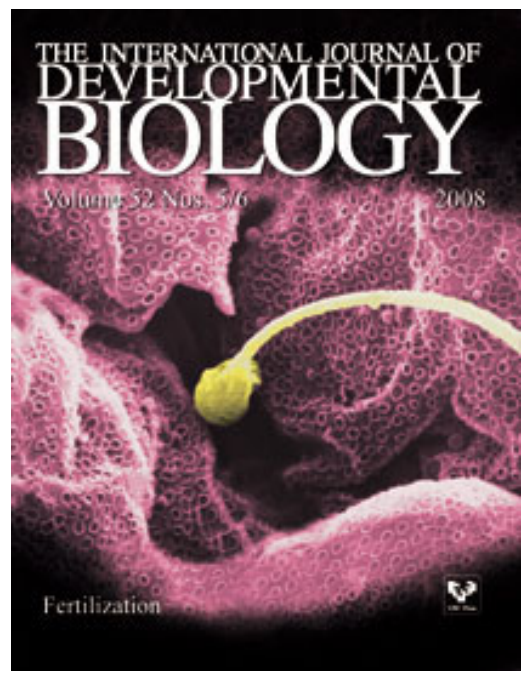

